\title{
A agenda da sustentabilidade global e sua pauta oficial: uma análise crítica na perspectiva da Saúde Coletiva
}

\author{
The official agenda of global sustainability: \\ a critical analysis from the perspective of Public $\mathrm{H}$ ealth
}

\author{
Gabriel Eduardo Schütz ${ }^{1}$ \\ Anamaria Testa Tambellini ${ }^{1}$ \\ Carmen Ildes Rodrigues Fróes Asmus ${ }^{1}$ \\ Armando M eyer ${ }^{1}$ \\ Volney de $M$ agalhães Câmara ${ }^{1}$
}

${ }^{1}$ Instituto de Estudos em

Saúde Coletiva,

UniversidadeFederal do

Rio deJaneiro. Praça Jorge

$M$ achado M oreira 100,

Cidade Universitária - Ilha

do Fundão. 21941-598 Rio

deJaneiro RJ.

gabriel@iesc.ufrj.br

\begin{abstract}
The scope of this article is to conduct a critical analysis from the perspective of Public Health of the first item of the Rio +20 Summit agenda: "A green economy in the context of sustainable development and the eradication of poverty." Methodologically, the analysis was performed through two converging approaches: (a) argumentative - by means of a dialectical analysis of facts and reports produced during the process; and (b) pragmatic - an analysis sof the socioenvironmental profile of the current twenty major economies in theworld, using indicators found in international agency databases. The results suggest that the greatest environmental pressure on natural resources is not poverty, as understood by the dominant agenda, but the historically de termined models of production.
\end{abstract}

Key words Sustainable development, Production, Environment, Public health
Resumo 0 objetivo do presente artigo é realizar, na perspectiva da SaúdeC ol etiva, uma análise crítica do primeiro ponto da pauta da Rio+20: “U ma economia verde no contexto do desenvolvimento sustentável eda erradicação da pobreza". M etodologicamente, a análise será desenvolvida por meio de dois caminhos confluentes: (a) argumentativo - através de uma análisedialética defatos erelatórios produzidos ao longo do processo; e, (b) pragmático - a partir de um perfil socioambiental das atuais vinte maiores economias do mundo, construído com indicadores pertencentes a bases de dados de agências internacionais. Os resultados sugerem que a maior pressão ambiental sobre os recursos naturais não é a pobreza, como entendida pela agenda dominante, mas as condições de produção historicamente determinadas.

Palavras-Chave Desenvolvimento sustentável, Produção, Ambiente, Saúde coletiva 


\section{Introdução}

Em junho de 2012 ocorrerá no Rio de Janeiro, Brasil, a Conferência das Nações Unidas sobre Desenvolvimento Sustentável (UNCSD), mais conhecida como Rio +20. 0 evento está pautado em dois temas princi pais: (a) uma economia verdeno contexto do desenvolvimento sustentável e da erradicação da pobreza; e (b) o quadro institucional para o desenvolvimento sustentável.

Rio+20 é parte de uma agenda internacional que vem gestando, a partir de 1972, a noção de "desenvolvimento sustentável" para denominar o processo de adaptação do capitalismo às novas condições de produção determinadas por mudanças políticas, culturais e ambientais desde a década de 1960, eque foram se aprofundando até o final do século XX. Por aqueles anos, uma série de crises estruturais e externas do capitalismo determinou a necessidade deestabelecer mudanças no regime de acumulação de capital; isto, logicamente, teverepercussões institucionais nos estados nacionais.

Entretanto, diversos atores sociais incluídos movimentos sociais e parte do mundo acadêmico, alertavam sobre a degradação e o eventual esgotamento dos serviços que os processos de produção material tomam dos ecossistemas; em especial, os de provisão de recursos naturais e energéticos.

0 reordenamento radical da economia capitalista, com alcance planetário, ocorreu a partir dos anos de 1980, tanto no material - com as reformas conservadoras de Reagan e Thatcher quanto no simbólico, com a queda do Muro de Berlim em 1989. O utro “muro" já tinha caído em 1987, com a desregulamentação do mercado financeiro internacional. A aplicação denovas tecnologias de informação e comunicação forneceu a infraestrutura necessária para organizar territórios em redes de produção, administração e distribuição de mercadorias em escala mundial; além de permitir a circulação irrestrita, eem tempo real, de capital financeiro através das fronteiras nacionais ${ }^{1}$.

Desde a formalização do Consenso de Washington, em 1989, e apesar de suas recorrentes crises estruturais, as reformulações caracterizadas como neoliberalismo foram consolidando sua hegemonia internacional. Uma hegemonia transformada no senso comum de multidões mediadas através de um relato monopólico insistentemente repetido em rede. 0 neoliberalismo impôs a sua legitimidade não apenas por mostrar resultados econômicos pragmáticos, mas principalmente por misturar com habilidade argumentos éticos e de justiça para criticar as desgastadas formas de intervenção estatal ${ }^{2}$. A política estava desprestigiada, o que favoreceu a instalação de significantes funcionais ao ideário neoliberal. Ao longo desse processo, a acumulação material da riqueza foi adquirindo modalidades mais "flexíveis", ao igual que a situação dos trabalhadores no mundo do trabalho ${ }^{3}$.

A governabilidade transformou-se em "governança"; com isto, as práticas políticas se reduziram ao gerenciamento empresarial do espaço público. Por isso, os ocupantes de cargos políticos se transformaram em "gestores" destinados a executar "diretrizes de gestão" no lugar de programas políticos de governo. Consequentemente, as questões públicas como saúde, educação e segurança passaram a ser administradas como sefossem mercadorias. Entretanto, as agências de cooperação internacional redobraram seus esforços para desenvolver metodologias capazes de produzir informações que, com rigor científico, auxiliassem esses gestores nos processos de formulação de políticas de gestão. Por esse caminho, aquilo que até a década de 1990 chamava-se genericamente de "estatísticas", úteis para monitorar programas políticos de governo, passou a denominar-se "indicadores", melhor adaptados à lógica gerencial.

Em busca de sua funcionalidade simbólica, "Economia verde" é o mais recente termo a entrar na pauta da agenda do capitalismo para administrar com "sustentabilidade" os recursos materiais e energéticos do planeta.

Processo de gestação

da agenda da sustentabilidade

A Conferência das Nações Unidas sobre De senvolvimento Sustentável (UNCSD) de 2012 marca o 40 aniversário da Conferência Internacional das $\mathrm{N}$ ações Unidas sobre o M eio Ambiente Humano (UNCHE) organizada em Estocolmo em 1972; o 20으 da Conferência das $N$ ações Unidas sobre M eio Ambiente eD esenvolvimento (UNCED), realizada no Rio de Janeiro em $1992 \mathrm{e}$ - 10 da Cúpula Mundial sobre Desenvolvimento Sustentável (WSSD), promovida em Johanesburgo em 2002.

Observe-se no percurso, que pa convocatória perdeu primeiro o componente "humano", presente em 1972, e depois o componente "meio ambiente", presente em 1972 e 1992. A hermenêutica indicaria que a pauta foi adquirindo um perfil cada vez mais econômico, entanto a psica- 
nálise explica que aquilo que incomoda, soe desaparecer do discurso. Presunções que se confirmariam se, daqui a vinte anos, fosse apagado também o qualificativo "sustentável" para denominar-se "Conferência sobre D esenvolvimento e Economia Verde".

Em boa medida, os nomes das conferências refletem os contextos históricos em que se realizam. A primeira delas, Estocolmo-72, teve uma convocação pautada na crise ambiental evidenciada desde a década de 1950, com impacto local visível em países industrializados. Contam exemplos como a poluição atmosférica em cidades como Londres, onde em 1952, matou 4.000 pessoas em sete dias; 0 aumento da acumulação de lixos urbanos e o fenômeno da chuva áci da ${ }^{4}$ dentre outros impactos ambientais associados à ação humana. Em 1962, a publicação do livro de Rachel Carson, "Primavera Silenciosa" sensibilizou o público sobre os efeitos da poluição química. Ainda, a posterior ocorrência deacidentes industriais em plantas químicas e em usinas nucleares ajudou a aumentar a percepção social de risco ambiental.

0 impulso desenvolvimentista de pós-guerra começou a perder fôlego a partir da crise do petróleo de 1973/74, evidenciando a fragilidade estrutural da matriz energética do capitalismo. Por outra parte, desde o maio francês de 1968, aumentou a diversificação ea expressividade dos conflitos sociais, incluindo reclamos pacifistas, feministas, étnicos e ecologistas, dentre outros.

Em 1972 obteve grande repercussão a publicação do Relatório "Os Limites do Crescimento", elaborado por uma equipe do M assachusetts Institute of Technology sob encomenda do Clube de Roma. Por meio demodelosmatemáticos, a equipe mostrou a incompatibilidade entre a capacidade de sustentação do planeta e o ritmo de crescimento das pressões humanas sobre os recursos. 0 documento influenciou o debate em Estocolmo-72, pois instal ou a noção de "crescimento zero" da economia mundial. Porém, essa posição só atraiu a atenção de expoentes de sociedades industriais que já tinham alcançado boas condições materiais de vida. 0 mesmo não aconteceu entre representantes de países como o Brasil, que buscavam a sua vez de desenvolver-se por meio da industrialização.

Depois da Estocolmo-72, a Europa diminuiu a pressão ambiental da poluição industrial; em parte, devido à implantação de controles das emissões poluidoras acordados na Conferência; em parte, devido ao transpasso das linhas de produção mais poluidoras a países que, em bus- ca do "desenvolvimento", ofereceram seus territórios. A consequência dessa política tem deixado passivos ambientais, principalmente químicos, até hoje não remediados e que continuam a contar vítimas graves e fatais.

Embora Estocolmo-72 tenha contado com uma escassa presença delíderes mundiais, o evento teve um notável impacto na incorporação da problemática ambiental nas políticas nacionais. Em 1971, apenas 12 países contavam com agências estatais específicas para questões ambientais. Dez anos depois, mais de 140 países tinham criado órgãos administrativos para esse setor ${ }^{5}$.

A Rio-92, pelo contrário, contou com uma presença maciça de chefes de estado, dando ao evento o nome "Cúpula da Terra". Em simultâneo, foi realizada a "Cúpula dos Povos", uma convocação paralela da que participaram um grande número de expoentes sociais contestatórios e público geral, convocados a discutir a sustentabilidade ambiental do planeta.

Desenvolvimento sustentável, o conceito deque nortearia a conferência já tinha sido definido em 1987 como: “um processo de transformação no qual a exploração dos recursos, a direção dos investimentos, a orientação do desenvolvimento tecnológico e a mudança institucional se harmonizam ereforçam o potencial presenteefuturo, a fim deatender àsnecessidades easpirações humanas" ${ }^{\prime \prime}$.

A Rio-92 se constituiu em um laboratório social onde confluíram sujeitos de duas globalizações dialeticamente opostas: (i) a gl obalização hegemônica, representada pela maioria dos representantes dos estados, das agências de cooperação internacional e do denominado "terceiro se tor", um grupo de organizações civis funcionais à economia de mercado e; (ii) a globalização contra-hegemônica, definida por Boaventura deSousa Santos como um conjunto vasto deredes, iniciativas, organizações e movimentos que lutam contra as consequências econômicas, sociais e políticas da globalização hegemônica, que se opõem a seu modelo de desenvolvimento ao mesmo tempo em que propõem concepções alternativas?

A conferência produziu documentos importantes, destacando-se a "Carta da Terra", uma declaração de princípios éticos; eum amplo programa de ação socioambiental multissetorial denominado "Agenda 21". Ambos obtiveram ampla aceitação, inclusive, dentre os portadores de ideias contra-hegemônicas em todo o planeta. Depois de Rio-92, o desafio pela frente consistia em como dar governança a um modelo de desenvolvimento que se propôs sustentar ambientalmente processos produtivos capitalistas. 
Processo de gestação da governança global da sustentabilidade

De acordo com Noam Chomsky, os conflitos sociais iniciados nos anos 1960 despertaram certo "medo da democracia" no establishment norte-americano. Em 1975, uma Comissão Trilateral dedicada ao estudo da "crise da democracia" entendeu que tinha se expandido uma espécie de "excesso de democracia", e aspirava à restauração dos tempos em que o presidente Truman, entre 1945 e 1953, foi capaz de governar os Estados Unidos com a ajuda de um número relativamente pequeno de advogados e banqueiros:

O bjeto deespecial preocupação da Comi ssão eram as deficiências do que ela considerava como instituições responsáveis "pela doutrinação dos jovens": escolas, universidades e igrejas. A fim de superar a crise da democracia, a comissão propôs formas de restaurar a disciplina e fazer com que o público em geral retomasse à passividade eà obediênciå ${ }^{8}$.

Estratégias deste tipo foram denominadas "biopolítica" por Michael Foucault9: o disciplinamento do corpo em espaços de vigilância permanente para evitar prematuramente "desvios" indesejados.

Em resumo, a pressão política exercida por movimentos sociais contra-hegemônicos na segunda metade do Século XX trouxe à baila a importância de contar com dispositivos disciplinadores que garantam a governabilidade dos conflitos sociais por meio de instituições funcionais consolidadas. Por esses anos, os meios massivos de comunicação passaram a jogar um papel fundamental no controle do pensamento nas democracias liberais ${ }^{10}$.

A precaução do status quo justifica-se no fato de que o conflito, como explicava George Sim$\mathrm{me}^{11}$, costuma atuar como catalisador de transformações no perfil dedistribuição material numa sociedade. Frequentemente, as demandas conflitantes toleradas pela ordem social dominante são aquelas cujas soluções não implicam transformações radicais da ordem econômica instituída.

Nesse sentido, Ernesto Laclau ${ }^{12}$ denomina demandas democráticas àquelas reclamações que, satisfeitas ou não, permanecem isoladas, constituindo identidades sociais fragmentadas, pequenos relatos. Em contrapartida, denomina demandas populares às que agregam a pluralidade através da articulação equivalente das demandas, produzindo subjetividades maisamplas, que podem vir a constituir-se em uma identidade política sintética, o povo, capaz de transformar-se em ator histórico, produzindo grandes relatos históricos.
Acompanhando a trajetória das reestruturações neoliberais, na década de 1990 nascia o conceito governança global: um novo paradigma de regulação social que veio suplantar o modelo anterior, baseado no papel privilegiado do Estado para regular o conflito social por via do poder de comando e de coerção ${ }^{7}$. Segundo a Comissão sobre Governança Global das Nações Unidas: "A governança é a totalidade das diversas maneiras pelas quais os indivíduos e as instituições, públicas ou privadas, administram seus problemas comuns. É um processo contínuo pelo qual é possível acomodar interesses conflitantes ou diferentes e realizar ações cooperativas"13.

Numa perspectiva crítica, a governançaéuma rede de ideias pragmáticas e de padrões de comportamento cooperativo, compartilhados por um grupo de atores selecionados, portadores de respectivos interesses; uma rede autoativada, destinada a lidar com o caos num contexto em que nem a ordem normativa exercida desde cima (comando estatal) nem o ordenamento participativo autônomo feito desde as bases (democracia participativa) estão disponíveis ou, caso estejam, não são desejáveis?. O bserve-se que os atores sociais que adentram na arena da governança são os "portadores de interesses" (stakeholders), e não os portadores de direitos (rigthholders). A governança não tem vocação universal, mas seletiva.

\section{O ideário hegemônico}

que pauta a agenda da sustentabilidade

Uma preocupação iniludível da governança global diz respeito à necessidade de planejar, executar emonitorar uma estratégia geopolítica, econômica e até militar destinada a garantir a apropriação, a distribuição e a utilização de recursos naturais estratégi cos que sustentam o modelo de acumulação de capital no plano internacional, ou seja, o desenho de uma "segurança ambiental" na agenda política da sustentabilidade.

Em 1995, a Comissão das Nações U nidas sobre Governança Global publicou seu relatório "Nossa Comunidade Global". Ao menos no campo da Saúde Coletiva, esse documento teve uma repercussão sensivelmentemenor do que o Relatório "Nosso Futuro Comum", publicado em 1987 pela Comissão das Nações Unidas sobre M eio Ambientee Desenvolvimento, mais conhecido como Relatório Brundtland. Porém, ambos são complementários: enquanto um introduziu a doutrina da sustentabilidade, o outro refletiu sobre as ferramentas políticas de sua execução.

No ideário desses relatórios, a sustentabilidade ambiental implica utilizar os recursos do 
planeta com critérios de solidariedade intergeracional para garantir que "os que virão" também tenham garantido seu acesso aos serviços ambientais. A mesma ênfase discursiva, porém, não é utilizada para reclamar 0 acesso universal aos serviços ecossistêmicos por parte dos atuais marginados e excluídos do modelo econômico. Esse acesso, em todos os casos, só se admite ser regulado pelas leis do mercado. No entanto, os pobres não estão ausentes no relatório sobre Governança M undial:

$N$ as nações em desenvolvimento, a principal pressão sobre o meio ambiente está vinculada à pobreza. Os pobres exercem pressões sobre os solose as florestas, explorando-os demasiadamente para sobreviver e solapando a base dos recursos da qual dependem seu bem estar e sua sobrevivência ${ }^{13}$.

Ou seja, os experts em governança global afirmam que são os pobres - e não o agronegócio osque, por meio de práticas predatórias, exercem a pressão sobre os solos e as florestas. N essa perspectiva, a força motriz que impulsiona as pressões é malthusiana: "O rápido crescimento demográfico está estreitamente ligado à questão da segurança ambiental pelo impacto que as pessoas exercem sobre os recursos vitais do planeta" ${ }^{13}$.

N esta perspectiva, quem exerce a pressão ambiental são "as pessoas" e não as relações materiais de produção historicamente construídas tais como monoculturas extensivas, uso intensivo dos solos, de fertilizantes sintéticos e de agrotóxicos, a irrigação e a manipulação dos ge nomas de plantas e animais domésticos. Isto explica o apelo a "nosso futuro" e "nossa comunidade" nos títulos dos documentos: não há responsabilidades nominais quando todos igualmente são responsáveis.

Ainda, perante a crise dos recursos naturais, o relatório exibeum raciocínio etnocêntrico, próprio do ideário colonialista das democracias liberais industrializadas:

Esses países devem ser ajudados a vencer a pobreza eassim aliviar as pressões sobre o seu hábitat. $M$ as, à medida que se tornarem menos pobres, seus padrões de vida e, consequentemente, seus níveis de consumo aumentarão. 0 mundo deve buscar meios de garantir que tais países atravessem esse processo sem por em perigo a segurança do meio ambiente [...] Para manter o uso dos recursos gl obais dentro delimites prudentes enquanto as populações pobres melhoram seu padrão devida, é preciso queas sociedades afluentes consumam menos ${ }^{13}$.

Observe-se que o relatório aponta com clareza que a segurança ambiental depende do tipo de desenvolvimento a ser seguido pelos "países pobres"; e esse risco justificaria reduzir o esbanjamento nas sociedades ricas.

0 termo "segurança ambiental" nasce do alargamento do conceito de segurança no início dos anos 80. M ais especificamente, aparece em um relatório publicado em 1982 pela Comissão IndependentesobreQuestões deD Desarmamento eSe gurança. Essa comissão considerou as várias ameaças à segurança comum que incluem, além das de tipo militar, diversas outras associadas a problemas econômicos, escassez derecursos, crescimento demográfico e destruição do ambiente ${ }^{14}$.

Nessa perspectiva, o documento sobre Governança Global advertia em 1995 que a implementação da Agenda 21, aprovada três anos antes, estava indissociavelmente ligada à questão dos recursos adicionais para 0 desenvolvimento ${ }^{13}$, em especial, por parte dos países "em desenvolvimento".

Todavia, a Agenda 21 resultaria problemática à ordem econômica global por duas questões principais: (i) o reconhecimento do Estado como legítimo formulador de políticas públicas que, eventualmente, poderiam "interferir" no laissez faire do capitalismo; e (b) o tipo de participação ampla e aberta dada aos grupos sociais organizados, aproximando-se demais à democracia participativa. Em consequência, embora pensada para ser implementada em níveis global, nacional e local, a Agenda 21 foi sendo restringida a iniciativas locais não muito decisivas no rumo do desenvolvimento econômico.

No plano internacional, foi implicitamente extinta em setembro de 2000, quando a 55a Assembleia da ONU aprovou outra agenda denominada Objetivos de Desenvolvimento do Milênio (M illenium Development Goals) com ênfase particular na erradicação da pobreza e seus efeitos evitáveis. Esta nova agenda, com prazo de cumprimento das metas estabel ecido para 2015.

Resumindo, o ideário hegemônico em relação à sustentabilidade poderia ser sintetizado em três pontos: (a) identificação do crescimento populacional em condições de pobreza como a principal força motriz impulsora da pressão sobre os recursos naturais vitais para os serviços ecossistê micos de provisão; (b) o monitoramento do desenvolvimento dos países ainda "não desenvolvidos" é uma questão de "segurança" global; e (c) 0 mundo desenvolvido deve "ajudar" tutorando os países que buscam desenvolver-se a "vencer a pobreza", se preciso, revisando seu próprio esbanjamento, promovendo a "sustentabilidade".

Explica-se, atéaqui, por quea Rio +20 foi pautada na discussão de "uma economia verde no 
contexto do desenvolvimento sustentável eda erradicação da pobreza". Resta agora analisar como foi sendo gestada a noção de Economia verde.

Quiçá porquea Agenda 21 dedicou seu capítulo 6 à "Proteção e fomento da saúde humana", este documento obteve - igual que o relatório Brundtland - grande repercussão dentre os sanitaristas. No entanto, outro documento divulgado em ocasião da Rio-92 passou quase desapercebido nas produções acadêmicas da Saúde Coletiva, trata-se do relatório "Mudando o rumo: uma perspectiva empresarial global sobre desenvolvimento e meio ambiente" produzido pelo World Business Council for Sustainable Development (WBCSD). Esse relatório sintetiza a agenda do capitalismo para o desenvolvimento sustentável, centrada no conceito de"Ecoeficiência", reformulado vinte anos depois como "Economia Verde".

Em 1992, a Ecoeficiência foi apresentada como uma política de gestão empresarial que incorpora a responsabilidade ambiental corporativa e encoraja as empresas de qualquer porte e setor a se tornarem mais inovadoras e competitivas qualitativamente ${ }^{15}$. Coerente com a lógica da governança hegemônica, essa proposta exprime formas de aderir voluntariamente a um determinado conjunto de normas gerenciais que, diferente da legislação do Estado nacional, não são nem obrigatórias nem de escopo universal.

A ideia da autorregulação amplia a adesão voluntária, incluindo a práxis empresarial efetiva. De acordo o WBCSD, uma empresa ecoeficiente é aquela que consegue pôr em prática quatro ferramentas inter-relacionadas: (i) Sistema de gestão ambiental (SGA); (ii) Certificação ambiental; (iii) Processos de produção mais limpos $(\mathrm{P}+\mathrm{L})$; e, (iv) Avaliação do ciclo de vida (ACV) ${ }^{15}$.

O principal objetivo almejado por uma empresa ao implantar um SGA éintroduzir diretrizes de gerenciamento quelhe permitam simultaneamente: (a) reduzir custos economizando no esbanjamento de materiais e energia durante os processos produtivos; (b) reduzir sua responsabilidade civil em relação a eventuais impactos negativos sobre o ambiente; e, (c) melhorar sua imagem pública por meio do marketing social. Por isto, o simples fato de implantar um SGA já é utilizado pelas empresas para sua autopromoção como "sustentáveis".

Os sistemas de SGA podem, voluntariamente, aderir a um programa de certificação voluntária, como o oferecido pelas N ormas ISO 14000 da International Organization for Standardization. Dados do Instituto de Recursos Mundiais ${ }^{16}$ indicam que, em 1995, havia em todo o mundo 257 empresas com sua gestão ambiental certificada com a norma ISO 14001, enquanto que em 2002 (último dado disponível) esse número tinha-se elevado a 49.462, revelando a relevância adquirida pela proposta da gestão ambiental autorregulada na agenda do desenvolvimento global. Todavia, poucas são as empresas que levam seu programa de ecoeficiência até o final, ou seja, até a ACV. Este procedimento Ihes permitiria ponderar os impactos ambientais de um produto em forma integrada, desde seu design até a disposição final do que restou do produto consumido, passando por todo o processo de fabricação e consumo (incluindo embalagem, transporte, utilização / reutilização e eventual reciclagem). N esse sentido, adotar procedimentos de $\mathrm{P}+\mathrm{L}$ significa escolher os procedimentos menos poluidores e demandantes de recursos disponíveis em cada etapa do processo de produtivo. Um caso de indiscutível sucesso da P $+L$ é constituído pela diminuição da utilização de substâncias que destroem a camada de ozônio. De acordo com o indicador de consumo da base de dados dos O bjetivos de Desenvolvimento do M ilênio ${ }^{17}$, todos os países avaliados reduziram marcadamente ou eliminaram sua utilização, substituindo-as por componentes inócuos. As dificuldades para avançar na implementação de $\mathrm{P}+\mathrm{L}$ nas ACV são, em grande medida, limitações tecnológicas, além dos custos financeiros.

Em síntese, no ideário hegemônico, a sustentabilidade se alcança por meio da busca autorregulada, norteada pelo mercado, de formas cada vez menos poluidoras e menos demandantes de recursos. Essa expertise gerencial, com o nome de Economia Verde, deve ser promovida principalmente nos países "menos desenvolvidos" em nome da segurança ambiental global.

Contudo, os indicadores produzidos pelas próprias agências multilaterais em relação às maiores economias do planeta parecem não confirmar a presunção que a pressão que ameaça a segurança ambiental do planeta possa ser dividida geopoliticamente por uma linha abissal entre países ricos e pobres.

As grandes economias do mundo, segundo indicadores internacionais

As Tabelas 1, 2, 3 e 4 apresentam inconsistências detectáveis nos perfis econômico, sociossanitário e de desempenhos ambientais, traçados a partir de indicadores internacionais, das 19 maiores economias nacionais do planeta, agrupadas 
no chamado Grupo dos 20 (G20). A conformação do grupo responde mais a critérios geopolíticos do que estritamente econômicos. A fim de estabelecer comparações entre os países não se incluiu a Comunidade Econômica Europeia (CEE), que compõe o G20 como bloco.

$\mathrm{Na}$ Tabela 1, os países do G20 aparecem ordenados pela sua capacidade de gerar prosperidade material medida em termos de Produto Interno Bruto (PIB), calculado em função da paridade do poder de compra (PPC). Em relação ao PIB nominal, calculado a preços correntes, considera-se que o cálculo por PPC permite estabelecer comparações entre economias diferentes com mais precisão. Ao relativizar a produção nacional de riqueza por habitante e população, resulta evidente que alguns países muito populosos diminuem a magnitude da riqueza gerada. O PIB per capita é um dos componentes selecionados para o cálculo do Índice de Desenvolvimento Humano (IDH), o que permitiria, a priori, caracterizar países como Índia e Indonésia como os mais "pobres" do grupo, apesar do volume da riqueza produzida pela nação como um todo. A tabela mostra ainda a heterogeneidade do PIB (PPC) per capita e do IDH exibida pelos países do grupo BRICS (Brasil, Rússia, Índia,
China eÁfrica do Sul), cuja relevância geopolítica tem adquirido destaque no mercado mundial na última década.

A Tabela 2 mostra o desempenho sociossanitário de países membros do G20. Esta tabela foi construída principalmente com indicadores que compõem a base de dados dos O bjetivos de $\mathrm{De}$ senvolvimento do M ilênio (ODM) e complementada com dados do relatório sobre desenvolvimento humano do PNUD (Programa das Nações Unidas para o Desenvolvimento). Somente foram incluídos os indicadores que apresentam dados para o maior número possível de países do G20, contudo, somente nove países dispõem deinformação secundária parcial mente completa nas bases consultadas. Devido a que os indicadores expressam magnitudes de diferentes naturezas, todos os resultados foram transformados em índices com valor 1 (um) para o melhor desempenho e 0 (zero) para o pior. Nos casos em que o maior valor indica pior desempenho, utilizou-se a fórmula I $=(\mathrm{V} \max -\mathrm{Vob}) /(\mathrm{V} \max -$ Vmin), onde I é o índice; V max é o valor máximo; Vmin é o valor mínimo e Vob o valor em comparação. N os casos contrários, utilizou-se como numerador o resultado da subtração (Vob-Vmin). A média aritmética de todos os in-

Tabela 1. Produto Interno Bruto (PIB), População, PIB per capita (PPC) e Índice de Desenvolvimento Humano (IDH) dos países do G20

\begin{tabular}{lcccc}
\hline \multicolumn{1}{c}{$\begin{array}{c}\text { Membro } \\
\text { do G-20 }\end{array}$} & $\begin{array}{c}\text { PIB (PPC) } \\
\text { (milhões U \$S) }\end{array}$ & $\begin{array}{c}\text { População } \\
\text { (milhões habitantes) }\end{array}$ & $\begin{array}{c}\text { PIB (PPC) per cápitac } \\
\text { (milhões U\$S) }\end{array}$ & IDH $^{\text {d }}$ \\
\hline Estados Unidos & 14657800 & 309,2 & 47406 & 0.910 \\
China & 10085708 & 1340 & 7527 & 0.687 \\
Japão & 4309532 & 127,4 & 33827 & 0.901 \\
Índia & 4060392 & 1210,2 & 3355 & 0.547 \\
Alemanha & 2940434 & 81,8 & 35947 & 0.905 \\
Rússia & 2222957 & 141,9 & 15666 & 0.755 \\
Reino Unido & 2172768 & 62,0 & 35045 & 0.863 \\
Brasil & 2172058 & 193,1 & 11248 & 0.718 \\
França & 2145487 & 65,4 & 32806 & 0.884 \\
Itália & 1773547 & 60,3 & 29412 & 0.874 \\
Coréia do Sul & 1459246 & 48,9 & 29841 & 0.897 \\
Canadá & 1330272 & 34,1 & 39011 & 0.908 \\
Turquia & 1115994 & 72,6 & 15372 & 0.699 \\
México & 1039272 & 112,2 & 9263 & 0.770 \\
Indonésia & 1029884 & 237,5 & 4336 & 0.617 \\
Austrália & 882362 & 22,3 & 39568 & 0.929 \\
Argentina & 642402 & 40,1 & 16020 & 0.797 \\
Arábia Saudita & 621993 & 27,1 & 22952 & 0.770 \\
África do Sul & 523945 & 49,3 & 10628 & 0.619 \\
\hline
\end{tabular}

Fontes: a FM I23; b $\mathrm{CIA}^{24 ;}$; cálculo próprio a partir dos dados de PIB (PPC) e de População; d U N DP - H uman Development Report $2011^{25}$ 
Tabela 2. Perfil sociossanitário de países membros do G20

\begin{tabular}{|c|c|c|c|c|c|c|c|c|c|c|c|c|c|c|c|}
\hline \multirow[t]{2}{*}{ País } & \multicolumn{2}{|c|}{$\begin{array}{l}\text { População que } \\
\text { vive com menos } \\
1 \text { U\$S/dia (PPP) }\end{array}$} & \multicolumn{4}{|c|}{$\begin{array}{c}\text { População } \\
\text { alfabetizada, 15-24 } \\
\text { anos, ambos sexos }\end{array}$} & \multicolumn{4}{|c|}{$\begin{array}{c}\text { Insuficiência ponderal } \\
\text { moderada ou severa em } \\
\text { crianças menores de } 5 \text { anos }\end{array}$} & \multicolumn{3}{|c|}{$\begin{array}{l}\text { Mortalidade } \\
\text { infantil de } \\
0 \text { a } 1 \text { ano }^{a}\end{array}$} & \multicolumn{2}{|c|}{$\begin{array}{l}\text { Mortalidade } \\
\text { Infantil de } \\
0 \text { a } 5 \text { anos }\end{array}$} \\
\hline & $\%$ & Índice & & $\%$ & & dice & $\%$ & & dice & & Taxa & íno & dice & Taxa & Índice \\
\hline Rússia & 0,0 & 1,000 & & 9,7 & & & l & & l & & 9 & 1,0 & 00 & 12 & 1,000 \\
\hline Turquia & 2,7 & 0,935 & & 7,8 & & 898 & 3,5 & & 969 & & 14 & 0,8 & 372 & 18 & 0,882 \\
\hline Argentina & 0,9 & 0,978 & & 9,2 & & 973 & 2,3 & & 998 & & 12 & 0,9 & 23 & 14 & 0,961 \\
\hline México & 3,4 & 0,918 & & 8,5 & & 935 & 3,4 & & 971 & & 14 & 0,8 & 372 & 17 & 0,902 \\
\hline Brasil & 3,8 & 0,909 & & 7,8 & & 898 & 2,2 & & 000 & & 17 & 0,7 & 795 & 19 & 0,863 \\
\hline China & 15,9 & 0,618 & & 9,4 & & 984 & 6,8 & & 889 & & 16 & 0,8 & 321 & 18 & 0,882 \\
\hline Indonésia & 18,7 & 0,550 & & 9,5 & & 989 & 19,6 & & 579 & & 27 & 0,5 & 8 & 35 & 0,549 \\
\hline África do Sul & 17,4 & 0,582 & & 7,6 & & 887 & 8,0 & & 860 & & 41 & 0,1 & 179 & 57 & 0,118 \\
\hline Índia & 41,6 & 0,000 & & 1,1 & & 000 & 43,5 & & 000 & & 48 & 0,0 & 00 & 63 & 0,000 \\
\hline \multirow[t]{2}{*}{ País } & \multicolumn{2}{|c|}{$\begin{array}{c}\text { Taxa de } \\
\text { mortalidade } \\
\text { materna }\end{array}$} & \multicolumn{3}{|c|}{$\begin{array}{l}\text { População } \\
\text { com acesso a } \\
\text { água potávela }^{\text {a }}\end{array}$} & \multicolumn{2}{|c|}{$\begin{array}{l}\text { População com } \\
\text { acesso a serviços } \\
\text { de saneamento }\end{array}$} & \multicolumn{2}{|c|}{$\begin{array}{l}\text { População } \\
\text { morando } \\
\text { em favelas }\end{array}$} & $\mathrm{IDH}^{\mathrm{b}}$ & \multicolumn{3}{|c|}{$\begin{array}{l}\text { Coeficiente } \\
\text { de Gini }^{b}\end{array}$} & \multirow{2}{*}{\multicolumn{2}{|c|}{$\begin{array}{l}\text { Índice } \\
\text { Socios- } \\
\text { sanitário }\end{array}$}} \\
\hline & Taxa & Índice & $\%$ & Ín & & $\%$ & Índice & $\%$ & Índice & Índice & ce $\overline{\mathrm{Val}}$ & lor & Índice & & \\
\hline Rússia & 39 & 0,959 & 93 & & & 8 & 0,921 & I & I & 0.755 & & & I & & 0,895 \\
\hline Turquia & 23 & 1,000 & 99 & & & 90 & 1,000 & 14,1 & 1,000 & 0,699 & & 9,7 & 1,000 & & 0,841 \\
\hline Argentina & 70 & 0,879 & 97 & 0,8 & & 90 & 1,000 & 23,5 & 0,478 & 0,797 & & 5,8 & 0,478 & & 0,807 \\
\hline M éxico & 85 & 0,840 & 94 & 0,7 & & 85 & 0,868 & 14,4 & 0,983 & 0,770 & 51 & 1,7 & 0,983 & & 0,800 \\
\hline Brasil & 58 & 0,910 & 97 & 0,8 & & 80 & 0,737 & 28,0 & 0,228 & 0,718 & & 3,9 & 0,228 & & 0,723 \\
\hline China & 38 & 0,961 & 89 & 0,4 & & 55 & 0,079 & 31,0 & 0,061 & 0,687 & 41 & 1,5 & 0,061 & & 0,587 \\
\hline Indonésia & 240 & 0,439 & 80 & 0,0 & & 52 & 0,000 & 23,0 & 0,506 & 0,617 & & 5,8 & 0,506 & & 0,433 \\
\hline África do Sul & 410 & 0,000 & 91 & 0,5 & & 77 & 0,658 & 28,7 & 0,189 & 0,619 & 57 & 7,8 & 0,189 & & 0,425 \\
\hline Índia & 230 & 0,465 & 88 & 0,4 & & 31 & $-0,553$ & 32,1 & 0,000 & 0,547 & & 5,8 & 0,000 & & 0,080 \\
\hline
\end{tabular}

Fontes. a M illennium Development Goals Indicator ${ }^{26}$. Dados atualizados em 2011. b U N DP - H uman D evelopment Report. Dados correspondentesa 201125. Todos os índices contidos na tabela foram elaborados pelos autores. Nos casos em que o maior valor indica pior desempenho, utilizou-sea fórmula I = (Vmax-Vob)/(Vmax - Vmin), ondel éo índice. Vmax éo valor máximo, Vmin éo valor mínimo eVob o valor em comparação. Nos casos contrários, o denominador éo resultado da subtração (Vob-Vmin).

dicadores foi denominada "índice sociossanitário". A posição dos países na tabela responde à ordem decrescente das performances nacionais para esse índice. Ao comparar com as posições ranqueadas nas Tabelas 1 e 2, resulta evidente que não existe uma associação direta entre a magnitude total ou relativa das economias nacionais com as performances sociossanitárias de cada país. As razões desta divergência não devem ser buscadas nos indicadores econômicos, mas na dialética dos processos produção material e cultural social, historicamente determinados, realizada em cada sociedade. Isto resulta evidente ao se comparar a disparidade de performances sociossanitárias exibidas pelos países do BRICS.

A Tabela 3 mostra o ranking dos países do G20, posicionados em relação a seu desempenho no "Índice $\mathrm{CO}_{2}$ " construído a partir de três indicadores: (i) emissões de dióxido de carbono
(CO2) em toneladas métricas ( $10^{3} \mathrm{t}$ ); (ii) emissões de CO 2 per capita, em $10^{3}$ t; e, (iii) emissões de $\mathrm{CO} 2$, em quilogramas de $\mathrm{CO} 2$ por $1 \mathrm{U} \$ \mathrm{~S}$ do PIB. $\mathrm{O}$ índice $\mathrm{CO}_{2}$ éum indicador sintético calculado a partir da média aritmética de seis índices, dois para cada indicador mostrado na Tabela 3: um ranqueando o desempenho de cada país segundo a magnitude total em 2008 (último ano com dados consolidados nas bases consultadas) e o outro ranqueando os respectivos coeficientes de variação porcentual entre 1992 (ano da Rio 92) e2008. Esta forma de cál culo visou rel ativizar reciprocamente o volume total emitido e as mudanças no padrão de emissões em cada país. Os resultados da tabela indicam que os países da CEE que compõem individualmente o G20 exibem o melhor desempenho. Contudo, quando se repara nas pobres performances da China e dos Estados Unidos, resulta evidente que a segu- 
rança ambiental do planeta não depende da pobreza nem do grau de desenvolvimento industrial das nações, mas da opção política por manter condições de produção material incompatíveis com uma distribuição mundial justa dos serviços ecossistêmicos.
Finalmente, na Tabela 4 os países do G20 aparecem ranqueados segundo seu desempenho no "Índice Verde", um indicador sintético calculado com o mesmo procedimento explicado acima a partir dos indicadores "Porcentagem do território nacional coberto por florestas" e "porcenta-

Tabela 3. Desempenho dos países do G20 em relação às emissões de dióxido de carbono $\left(\mathrm{CO}_{2}\right)$



Fontes: M illennium Development Goals Indicator ${ }^{26}$. Dados atualizados em 2011. Todos os índices e os coeficientes porcentuais de variação $(\Delta \%)$ contidos na tabela foram elaborados pelos autores. 
Tabela 4. Desempenho dos países do G20 em relação à superfície coberta por florestas e por áreas de proteção ambiental

\begin{tabular}{|c|c|c|c|c|c|c|c|c|c|c|c|}
\hline \multirow{2}{*}{$\begin{array}{l}\text { Membro } \\
\text { do G20 }\end{array}$} & \multicolumn{5}{|c|}{ Território coberto por florestas (\%) } & \multicolumn{5}{|c|}{$\begin{array}{c}\text { Áreas territoriais e marinhas protegi das } \\
\text { em relação à superfície total }(\%)\end{array}$} & \multirow{2}{*}{$\begin{array}{l}\text { Índice } \\
\text { Verde }\end{array}$} \\
\hline & 1990 & 2010 & Índice 1 & $\Delta \mathrm{p} \%$ & Índice 2 & 1992 & 2010 & Índice 1 & $\Delta \%$ & Índice 2 & \\
\hline Itália & 25,8 & 31,1 & 0,450 & 5,3 & 1,000 & 4,79 & 15,86 & 0,345 & 231,1 & 0,535 & 0,582 \\
\hline Alemanha & 30,8 & 31,8 & 0,460 & 1 & 0,769 & 32,74 & 42,29 & 1,000 & 29,2 & 0,061 & 0,573 \\
\hline M éxico & 36,2 & 33,3 & 0,482 & $-2,9$ & 0,559 & 2,24 & 11,86 & 0,246 & 429,5 & 1,000 & 0,572 \\
\hline Brasil & 69,0 & 62,4 & 0,910 & $-6,6$ & 0,360 & 9,57 & 26,0 & 0,596 & 171,7 & 0,396 & 0,566 \\
\hline Arábia Saudita & 0,5 & 0,5 & 0,000 & 0 & 0,715 & 7,25 & 29,95 & 0,694 & 313,1 & 0,727 & 0,534 \\
\hline Japão & 68,4 & 68,5 & 1,000 & 0,1 & 0,720 & 7,67 & 10,91 & 0,222 & 42,2 & 0,092 & 0,509 \\
\hline França & 26,4 & 29,0 & 0,419 & 2,6 & 0,855 & 9,28 & 17,1 & 0,376 & 84,3 & 0,191 & 0,460 \\
\hline Rússia & 49,4 & 49,4 & 0,719 & 0 & 0,715 & 5,12 & 9,19 & 0,180 & 79,5 & 0,179 & 0,448 \\
\hline China & 16,7 & 21,9 & 0,315 & 5,2 & 0,995 & 13,15 & 16,04 & 0,349 & 22,0 & 0,044 & 0,426 \\
\hline Coréia do Sul & 64,5 & 63,0 & 0,919 & $-1,5$ & 0,634 & 3,92 & 5,01 & 0,076 & 27,8 & 0,058 & 0,422 \\
\hline Estados Unidos & 32,3 & 33,2 & 0,481 & 0,9 & 0,763 & 13,07 & 13,66 & 0,290 & 4,5 & 0,004 & 0,385 \\
\hline Canadá & 34,1 & 34,1 & 0,494 & 0 & 0,715 & 3,81 & 6,17 & 0,105 & 61,9 & 0,138 & 0,363 \\
\hline Reino Unido & 10,8 & 11,9 & 0,168 & 1,1 & 0,774 & 15,58 & 18,06 & 0,400 & 15,9 & 0,030 & 0,343 \\
\hline Austrália & 20,1 & 19,4 & 0,278 & $-0,7$ & 0,677 & 8,30 & 12,47 & 0,261 & 50,2 & 0,111 & 0,332 \\
\hline Índia & 21,5 & 23,0 & 0,331 & 1,5 & 0,796 & 4,68 & 4,82 & 0,071 & 3,0 & 0,000 & 0,299 \\
\hline Turquia & 12,6 & 14,7 & 0,209 & 2,1 & 0,828 & 1,81 & 1,94 & 0,000 & 7,2 & 0,010 & 0,262 \\
\hline Indonésia & 65,4 & 52,1 & 0,759 & $-13,3$ & 0,000 & 4,31 & 6,42 & 0,111 & 49,0 & 0,108 & 0,244 \\
\hline África do Sul & 7,6 & 7,6 & 0,104 & 0 & 0,715 & 6,48 & 6,88 & 0,122 & 6,2 & 0,007 & 0,237 \\
\hline Argentina & 12,7 & 10,7 & 0,150 & -2 & 0,608 & 4,91 & 5,25 & 0,082 & 6,9 & 0,009 & 0,212 \\
\hline
\end{tabular}

Fonte: M illennium Development Goals Indicator ${ }^{26}$. Todos os índices e os coeficientes porcentuais de variação ( $\ddot{A} \%$ ) contidos na tabela foram elaborados pelos autores.

gem das áreas territoriais e marinhas protegidas em relação à superfície total". Estes indicadores, junto com os indicadores de emissões de $\mathrm{CO} 2 \mathrm{e}$ de consumo de substâncias que destroem a camada de ozônio, embora insuficientes para traçar um perfil ambiental satisfatório, são os indicadores mais consolidados na base de dados dos ODM para a M eta 7 "Garantir a sustentabilidade ambiental"17. Os resultados da Tabela 4 mostram, em primeiro lugar, as limitações metodológicas da análise comparativa do desempenho por meio deindicadores ambientais de países com territorialidades tão diferentes. Observe-se que Arábia Saudita, com apenas 0,5\% do território nacional coberto por florestas em 2010 aparece ranqueada próximo ao Brasil, com $62,4 \%$, por ter quase triplicado a superfície de suas áreas protegidas. Por outro lado, o fato do Japão apresentar a maior superfície coberta por florestas dentre os países do G20 evidencia que os critérios observados para a construção do indicador são duvidosos, uma vez que considera como equivalentes bosque e plantação. Esta observação vale também na analise da situação do país pior ranqueado na tabela: Argentina, que na sua mais recente expansão da fronteira agrícola, tem desmatado milhões de hectares de seus escassos bosques (as terras áridas e semiáridas ocupam $75 \%$ do território nacional ${ }^{18}$ ). Estima-se que a Argentina perde uma média de 821 hectares de bosque por dia eque a maior parte dessas terras é utilizada para monocultura de soja ${ }^{19}$. Contudo, o uso insustentável do solo na Argentina não é exercido pela pressão demográfica dos pobres, como sugere a Comissão sobre Governança Global, mas por um grupo de produtores agrícolas que introduziram reestruturações nas condições de produção agrícola impulsionadas pelo alto valor internacional de suas commoditie ${ }^{20}$. N este processo, 0 alimento vira mercadoria. Por outro lado, a superfície ocupada pelas florestas nativas (bosques) na Argentina (28,7 106 ha) representa metade da superfície ocupada por plantações florestais $\left(63,310^{6} \mathrm{ha}\right)^{21}$. Isto sugere que a perda de "área coberta por floresta" no país sul-americano tenha ocorrido a expensas do bosque nativo, um recurso com menor valor de mercado do queas monoculturas florestais. Finalmente, cabe destacar que os indicadores dos ODM para a meta de sustentabilidade ambiental não incluem a pressão que representa a utilização de milhões de toneladas de produtos químicos, fertilizantes e agrotóxicos, associadas a este modelo de produção agrícola. 


\section{Considerações Finais}

A produção acadêmica da Saúde Coletiva deve incorporar de forma crítica conceitos como desenvolvimento sustentável, gestão ambiental e governança, pautados numa agenda de sustentabilidade global queatendecom prioridadeosinteresses econômicos das nações mais industrializadas.

Uma das conclusões da discussão apresentada neste artigo diz respeito às limitações eàs nuances relacionadas à produção de indicadores ambientais, tanto em termos do marco teórico conceitual da interface entre a economia política e o ambiente, quanto à insuficiência do atual sistema de informações. É evidente que os indicadores internacionais disponíveis não conseguem dar conta da realidade material em suas diversas expressões de determinação socioambiental. N esse sentido, corresponde ao campo da Saúde Coletiva explorar, analisar e comunicar com rigor científico os processos históricos condicionantes e determinantes da qualidade de vida da população. É nesseespaço epistemológico que seencontram as pressões ambientais de origem humana, não no neo-malthusianismo.

É preciso rediscutir o papel social da pesquisa científica nos países sul-americanos para que seus pesquisadores adotem uma atitude descoIonizada, e estejam atentos para não aderir acriticamente aos ideários que vêm pré-fabricados por agências que expressam a cosmovisão etnocêntrica do N orte. Isto implica queas nações que buscam melhorar as condições materiais de vida da sua população não devem repetir os erros do passado, buscando um modelo de desenvolvimento econômico que ofereça prosperidade no curto prazo e ao preço da destruição ambiental, determinando agravos à saúde de sua população no meio e longo prazo.

Vencer a pobreza não significa criar nichos de mercado que insiram multidões nas práticas deconsumo, mas criar as condições para a emancipação e o desenvolvimento humano, que podem não acompanhar o poderio econômico, como indicam as disparidades entre PIB eIDH apresentadas acima.

Vale destacar que, nesta conjuntura, as instituições onde o conhecimento é produzido devem: (a) hierarquizar as condições de produção, avaliação edivulgação da produção dos seus pesquisadores, orientando-a às necessidades sociais da população local; sem ignorar os condicionamentos impostos pela globalização hegemônica ainda vigente, mas contribuindo para a construção deuma globalização diferente, mais justa e fraterna; e, (b) proteger a autonomia ea independência de seus pesquisadores, hoje vulneráveis às pressões, diretas ou indiretas, dos poderes político e econômico dominantes ${ }^{22}$.

Por esse caminho, o campo da Saúde Coletiva estará também em condições mais fortalecidas de debater se é suficiente a economia verde para vencer a pobreza sem enfrentar estruturalmente o capitalismo.

\section{Colaboradores}

GE Schütz trabalhou na concepção teórico-conceitual emetodológica ena redação final. AT Tambellini trabalhou na concepção teórico-conceitual ena revisão final. CIR Fróes Asmus trabal hou na concepção metodológica e na pesquisa. A M eyer trabalhou na concepção metodológica e na revisão final. VM Câmara trabalhou na concepção teórico-conceitual e metodológica e na revisão final. 


\section{Referências}

1. Castells M. Tecnologia da Informação e capitalismo global. In: Hutton W, Giddens A, organizadores. No limite da racionalidade: convivendo com 0 capitalismo global. Rio de Janeiro: Record; 2004. p. 81-111.

2. De Vita A. A justiça igualitária e seus críticos. São Paulo: Editora UNESP; 2000.

3. Antunes R. Adeus ao Trabalho: Ensaio sobre as M etamorfoses e a Centralidade do Mundo do Trabalho. São Paulo, Campinas: Editora Cortez, Editora da Unicamp; 2003.

4. Miranda AC, Tambellini AT, Moreira JC. As relações entre o modelo de desenvolvimento e os impactos sobre o ambiente e a saúde humana: uma revisão do cenário atual. Cad Saude Colet 2011; 19(3): 251-263.

5. Leis HR. A modernidade insustentável: As críticas do ambientalismo à sociedade contemporânea. Petrópolis, Florianópolis: Vozes; UFSC; 1999.

6. Comissão Mundial sobre M eio Ambiente e Desenvolvimento. Nosso Futuro Comum. Rio de Janeiro: Editora da Fundação; 1988.

7. Santos BS. A crítica da governação neoliberal: 0 Fórum Social Mundial como política e legalidade cosmopolita subalterna. Revista Crítica de Ciências Sociais 2005; 72:7-44.

8. Chomsky N. O lucro ou as pessoas: Neoliberalismo e ordem global. Rio de Janeiro: Bertrand Brasil; 2002.

9. Foucault M. História da Sexualidade: a vontade de saber. Rio de Janeiro: Edições Graal; 1988.

10. Chomsky N. Ilusiones necesarias: control del pensamiento en las sociedades democráticas. La Plata: Terramar; 2007.

11. Simmel G. Conflict and the Web of Group-Affiliations. Toronto: First Free Press Paperback Edition; 1964.

12. Laclau E. La razón populista. Buenos Aires: Fondo de Cultura Econômica; 2008.

13. Comissão sobre Governança Global. N ossa Comunidade Global. Rio de Janeiro: Editora da Fundação Getúlio Vargas; 1996.

14. Veiga LC. Segurança ambiental: o ambiente como factor de segurança. Janus 1998; Suplemento das Forças Armadas. [acessado 2012 maio 1]. Disponível em: http://janus.ual.pt/janus.anuario/1998fa/ 1998fa_1_10.html

15. Almeida $\bar{F}$. O Bom Negócio da Sustentabilidade. Rio de Janeiro: N ova Fronteira; 2002.

16. World Resources Institute (WRI). Corporations: Number of certified ISO 14001 companies. 2002. [acessado 2012 maio 1]. Disponível em: http://earthtrends. wri.org/
17. M illennium Development Goals Indicators (UN STAT). Consumption of all O zone-D epleting Substances in ODP metric tons. 2009. [acessado 2012 maio 1]. Disponível em: http://unstats.un.org/unsd/mdg/ Data.aspx

18. Roig FA, Gonzalez Loyarte $M$, Abraham $E$, M éndez E, Roig V, Martínez Carretero E. Maps of desertification Hazards of Central Western Argentina, ( $M$ endoza Province). Study case. In: U nited $\mathrm{Na}$ tions Environmental Program (UNEP). World Atlas of thematic Indicators of Desertification. London: Arnold; 1991. p. 69-69.

19. Rulli J. La expansión de la soja en Latinoamérica. In: Rulli J, organizador. Repúblicas Unidas de la Soja: realidades sobre a producción de soja en América del Sur. Buenos Aires: GRR; 2007.

20. Craviotti C. Los nuevos productores: alimentos de alto valor y reestructuraciones agrarias. Buenos Aires: Ediciones Ciccus; 2008.

21. Argentina. Instituto Nacional de Estadísticas y Censos (INDEC). Superficie de bosques por tipo, según provincia y región natural. 1998/2006. [acessado 2012 maio 1]. Disponível em: http://www.indec.mecon. ar/nuevaweb/cuadros/11/Q 010113.xls

22. Schütz G. A Ciência, a Justiça e os dilemas do Desenvolvimento Econômico. Cad Saude Coletiva 2011; 19(3):249-250.

23. Fundo Monetário Internacional,World Economic Outlook Database. Dados referentes ao ano de 2010. [acessado 2012 maio 1]. Disponível em: http:// www.imf.org/external/data.htm

24. CIA World Factbook. Dados referentes ao ano de 2010. [acessado 2012 maio 1]. Disponível em: https:// www.cia.gov/library/publications/the-world-factbook/index.html

25. UNDP - Human Development Report. Dados correspondentes a 2011. [acessado 2012 maio 1]. Disponível em:http://hdr.undp.org/en/statistics/ihdi/

26. Millennium Development Goals Indicator. Dados atualizados em 2011. [acessado 2012 maio 1]. Disponível em: http://unstats.un.org/unsd/mdg/Data.aspx

Artigo apresentado em 09/04/2012

Aprovado em 12/04/2012

Versão final apresentada em 25/04/2012 